\title{
AÇÃO ANTIMICROBIANA E INTERAÇÃO ENDOFÍTICA EM SYMPHYTUM OFFICINALE L.
}

\author{
ANTIMICROBIAN ACTION AND ENDOPHYTIC \\ INTERACTION IN SYMPHYTUM OFFICINALE L.
}

\author{
MARCOS PILEGGI ${ }^{1}$ \\ P. M. RAIMAM ${ }^{2}$ \\ A. MICHELI ${ }^{2}$ \\ S. BEATRIZ ${ }^{2}$ \\ V. BOBATO ${ }^{2}$
}

1 Professor do Departamento de Biologia Estrutural, Molecular e Genética da UEPG

2 Acadêmicos do Programa de Iniciação Científica da UEPG

\section{RESUMO}

Atualmente, as plantas medicinais vêm sendo estudadas a partir de pressupostos de interações endofíticas, as quais tem apresentado muitos benefícios, como produtores de antibióticos, metabólicos secundários de interesse farmacológico, bioindicadores de vitalidade, agentes de controle biológico de pragas e doenças entre outros. Nosso estudo foi baseado em Symphytum officinale, conhecida vulgarmente por Confrei, que apresenta propriedades terapêuticas como ação antiinflamatória, cicatrizante, antipsoríase , antiirritante , hidratante e outras. Utilizamos uma folha da planta que foi desinfestada e teve seu limbo e pecíolo cortados em pedaços pequenos e devidamente distribuídos em 10 placas de Petri contendo Ágar Sangue. Após o crescimento dos microrganismos, isolamos os 
mesmos em Caldo Nutriente para posterior inoculação em meio Ágar Nutriente com duas bactérias, Staphylococcus aureus e Klebsiella pneumoniae. Desta maneira, observamos a inibição do crescimento da bactéria S. aureus pelo microrganismo endofítico que por analise de lâminas verificou-se ser um fungo, demonstrando desta maneira a propriedade antimicrobiana provavelmente por parte do fungo e não pela planta.

Palavras-chave: interação endofitica; ação antimicrobiana; Symphytum officinale; Staphylococcus aureus

\section{Introdução}

A planta herbácea Symphytum officinale pertencente à família Boraginaceae, conhecida popularmente por Confrei é utilizada em larga escala na medicina popular, dentre as propriedades terapêuticas encaixamse ação antiinflamatória, cicatrizante, antipsoríase, emoliente e ligeiramente adstringente, porém seu uso via oral não é indicado pois causa reações adversas no fígado.

Segundo Matos (1994), a pomada e o cozimento são usados como ótimo cicatrizante, para tratamento local de ferimentos, úlceras e queimaduras com fogo, água quente ou por exposição demorada ao sol.

O presente trabalho teve por objetivo o isolamento do microrganismo endofítico e verificar se há propriedade antimicrobiana.

Microrganismos endofíticos, geralmente fungos e bactérias, interagem e vivem sistematicamente no interior das plantas, sem causar aparentemente dano a seus hospedeiros.

Existe uma série de razões para que se aprofundem os estudos com endofíticos pois, vários deles são capazes de produzir antibióticos e outros metabólicos secundários de interesse farmacológico, muitos têm sido usados como agentes de controle biológico de pragas e doenças e também como bioherbicidas. 


\section{Materiais e métodos}

O método para a avaliação da hipótese iniciou-se com a desinfestação da folha de Symphytum officinale com solução de hipoclorito de sódio a 10\% utilizando "Swabs". Fez-se tamanhos de explants do limbo e pecíolo e colocados separadamente em meio Ágar Sangue (peptona de gelatina 5,7 g/L, extrato de carne 3,0 g/L, ágar bacteriológico 15,0 g/L, sangue $1 \mathrm{~mL}, \mathrm{pH}$ final 6,9 a $25^{\circ} \mathrm{C}$ ), num total de dez placas, sendo 5 com cortes do limbo e 5 com cortes do pecíolo, que foram posteriormente, incubadas a $37^{\circ} \mathrm{C}$ por 48 horas. Foram retiradas pequenas amostras do material crescido nas placas e passadas para $5 \mathrm{~mL}$ de cultura Caldo Nutriente e incubados a $37^{\circ} \mathrm{C}$ por 12 horas.

Após este período, amostras retiradas da cultura em Caldo Nutriente (peptona de gelatina 5,0 g/L, extrato de carne 3,0 g/L, com pH final 6,9 a $25^{\circ} \mathrm{C}$ ) foram inoculadas em culturas de Ágar Nutriente juntamente com bactérias controle, Staphylococcus aureus e Klebsiella pneumoniae, e em seguida as placas foram incubadas a $37^{\circ} \mathrm{C}$ por 24 horas.

Foram confeccionadas lâminas pelo método de coloração de Gram, para a identificação de microrganismos que se desenvolveram nas culturas.

\section{Resultados}

A análise feita com as 10 placas de meio Ágar-sangue contendo os explants da planta nos mostrou que somente 4 placas tiveram crescimento de fungos, como segue na Tabela 1.

Tabela 1 - Crescimentos de fungos em meio Ágar Sangue

\begin{tabular}{|l|c|c|c|c|c|c|c|c|c|c|}
\hline PLACAS & L-A & L-B & L-C & L-D & L-E & P-1 & P-2 & P-3 & P-4 & P-5 \\
\hline CRESCIMENTO & + & + & - & - & - & + & - & + & - & - \\
\hline
\end{tabular}

Legenda:

L: limbo (letras correspondem a quantidade de placas)

$\mathrm{P}$ : pecíolo (números correspondem a quantidade de placas) 
Na placa L-A (figura 2), formou-se um grande tapete de fungos esbranquiçado ao redor do explants seguido por $0,8 \mathrm{~cm}$ de halo, o restante da placa apresentou um crescimento bacteriano. A placa L-B (figura 1), apresentou o crescimento de fungos formando um tapete esbranquiçado de aparência rugosa e ausência de halo. Na placa P-1 (figura 3), houve o crescimento disperso de um tapete de fungos esbranquiçado e na placa P-3 (figura 4), formou-se ao redor do corte um tapete de fungos de coloração esbranquiçada com presença de um curto halo. Os resultados negativos apresentaram somente crescimento bacteriano por toda a placa, com a ausência de crescimento do endofítico em foco, consequentemente ausência de halo.

Após a incubação por 12 horas dos tubos de ensaio contendo Caldo Nutriente e amostras dos crescimentos positivos de fungos apresentados na tabela anterior, constatou-se o aparecimento de películas conforme a Tabela 2.

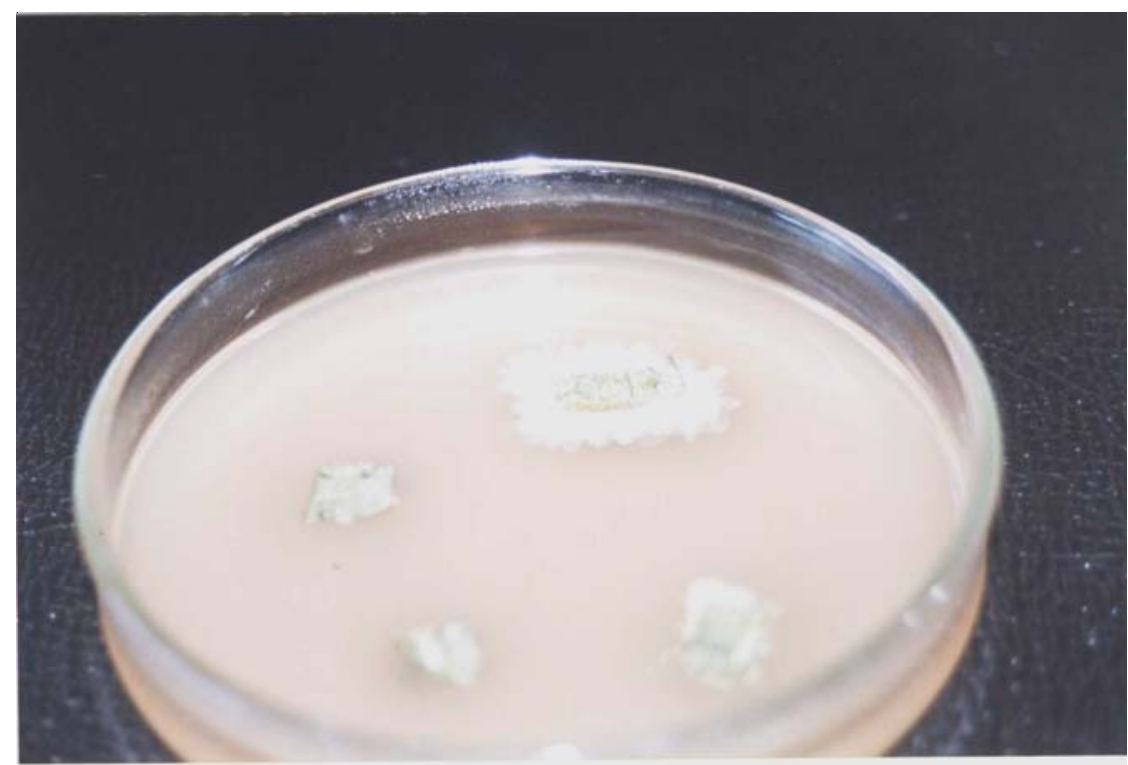

Figura 1: Cultura da amostra L-B em meio Ágar-sangue. 


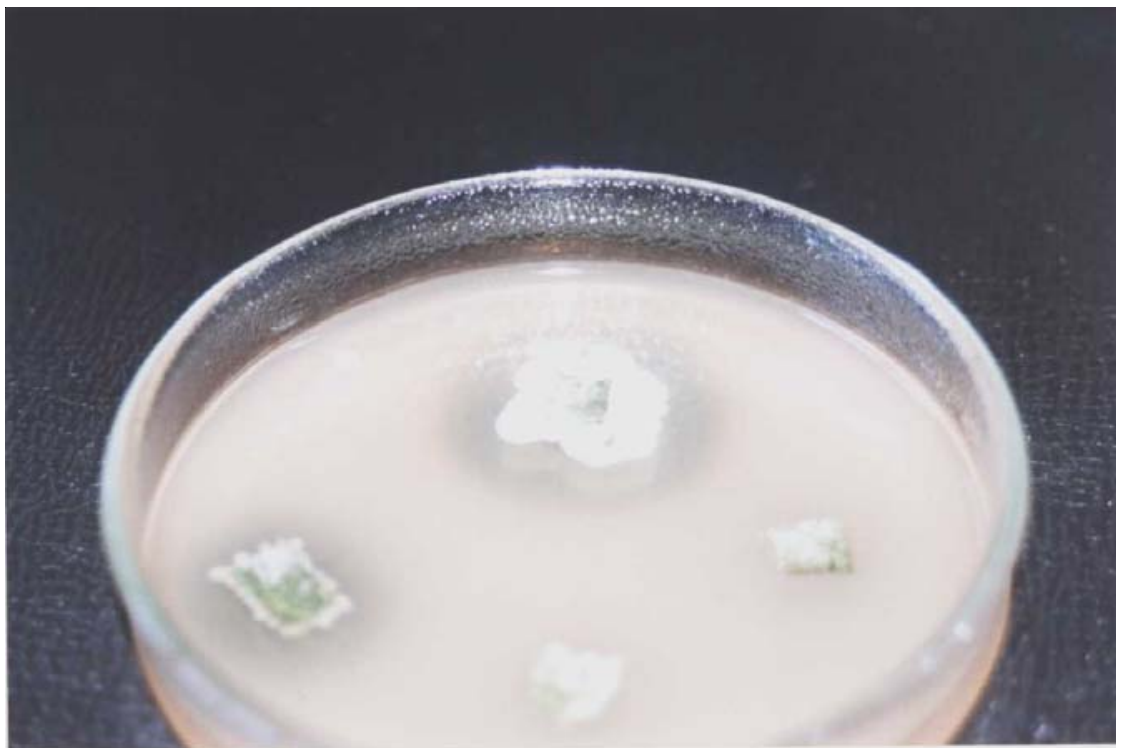

Figura 2: Cultura da amostra L-A em meio Ágar-sangue.

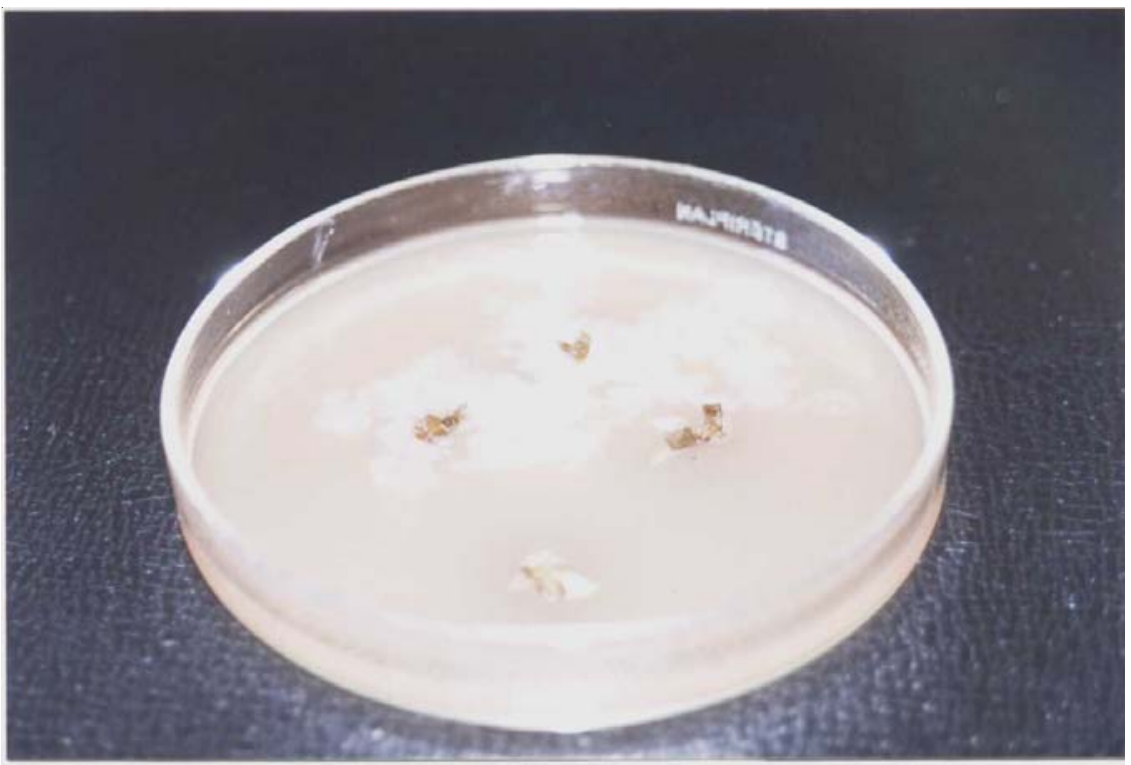

Figura 3: Cultura da amostra P-1 em meio Ágar-sangue.

PUBLICATIO UEPG - Biological and Health Sciences, 8 (1): 47-55, 2002. 


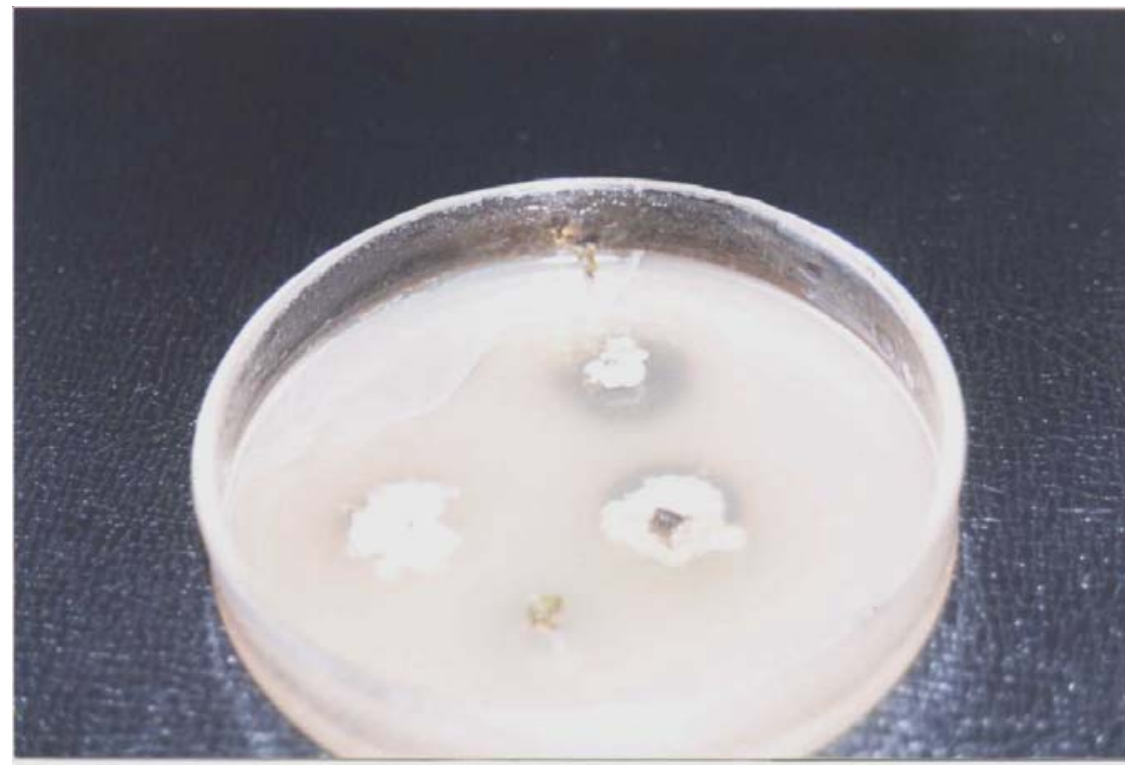

Figura 4: Cultura da amostra P-3 em meio Ágar-sangue.

Tabela 2 - Crescimento de películas em meio Caldo Nutriente

\begin{tabular}{|l|c|c|c|c|}
\hline TUBOS & L-A & L-B & P-1 & P-3 \\
\hline PELÍ́CULA & - & + & - & + \\
\hline
\end{tabular}

\section{Legenda:}

L-A: tubo contendo explante do limbo A

L-B: tubo contendo explante do limbo B

P-1: tubo contendo explante do pecíolo 1

P-2: tubo contendo explante do pecíolo 2

O meio de cultura do tubo contendo amostras de L-A tornou-se turvo, o tubo contendo amostras de L-B apresentou a formação de uma película fina e esbranquiçada somente na superfície da cultura, o mesmo aconteceu com o tubo contendo amostras de P-3. O tubo P-1 não apresentou nenhuma modificação. 
Por meio da coloração de Gram com as amostras dos 4 tubos pudemos observar a presença de micélios, bacilos e coccos.

As placas contendo as bactérias controle juntamente com fungos endofíticos foram analisadas após 24 horas de incubação a $37^{\circ} \mathrm{C}$ e verificou-se a inibição ou proliferação bacteriana, conforme segue na tabela 3 .

Tabela 3 - Inibição ou proliferação bacteriana em Ágar Nutriente

\begin{tabular}{|c|c|c|}
\hline BACTÉRIAS & Staphylococcus aureus & Klebsiella pneumoniae \\
\hline LIMBO A & -- & - \\
\hline LIMBO B & -- & + \\
\hline PECÍOLO 1 & -- & + \\
\hline PECÍOLO 3 & --- & + \\
\hline
\end{tabular}

Legenda:

---: inibição total do crescimento bacteriano

--: inibição parcial do crescimento bacteriano

+: proliferação bacteriana

\section{Discussão}

Foi utilizado um meio de cultura rico pois não tínhamos idéia das exigências nutricionais dos endofíticos.

Como o crescimento dos microorganismos não foi homogêneo nas placas, supomos que alguns passos metodológicos podem ter interferido, como por exemplo a concentração do hipoclorito de sódio utilizado na desinfestação da folha ou a escolha aleatória dos cortes, pois foi realizado o corte total do limbo e pecíolo, e a escolha dos explants foi ao acaso, não sendo utilizados todos os cortes de explant.

À partir do aparecimento do halo, subentende-se a presença de microrganismo endofítico que produz uma substância com ação bactericida/ bacteriostática. Porém em outras placas não houve o crescimento do halo podendo representar a presença de um microrganismo distinto daquele que produziu o halo. 


\title{
5. Conclusão
}

Por meio da análise das lâminas, nas quais ocorreram micélios, concluímos que o microorganismo é um fungo endofítico que pode atuar eficientemente sobre a bactéria Gram positiva, Staphilococcus aureus, inibindo seu crescimento. Acreditamos que este fungo produza um metabólito que possui tal característica.

Considerando que a bactéria citada, S. aureus, é uma das mais constantes em infecções hospitalares, podendo causar doenças sistêmicas, infecções cutâneas, doenças das vias urinárias entre outras, é de suma importância que existam meios de se minimizar seus efeitos. Progressos nas pesquisas desta área podem proporcionar o aprimoramento da utilização dos produtos do metabolismo dos microorganismos endofíticos pela indústria farmacêutica.

Recebido para publicação em 11/06/2002.

Aceito para publicação em 02/10/2002.

\begin{abstract}
Nowadays, the medicinal plants have been studied because the endophytic interactions, that have been showed a lot of benefits, like antibiotics producers, secundary metabolics of pharmacological interest, biological indicators of vitality, biological control agents of plagues and diseases, and others. In this way, our study was based in S. officinale, know in Brazil as "Confrei", that shows therapeutic proprierty like antiinflamatory action, moister and others. We use a leaf of the plant that was desinfestated and has its blade and petiolo cutted in small pieces and scarced in ten Petri plates with Nutrient Agar. After the microrganisms development they were inoculated in Nutrient Broth for further inoculation with two bacteries: Stafilococcus aureus and Klebsiella pneumoniae. We observed that just S. aureus growth were inibited by the endophytic fungus, showing that the antimicrobian proprierty exist by the endophytic fungus and not the plant active proprierty.
\end{abstract}

Key words: endophytic microrganism; amtimicrobian action; Staphylococcus aureus; Symphytum officinale

Endereço para contato: mpileggi@onda.com.br / mpileggi@uepg.br

(42) 220-3126

PUBLICATIO UEPG - Ciências Biológicas e da Saúde, 8 (1): 47-55, 2002. 


\section{REFERÊNCIAS}

1 MATOS, F.J.A. Farmácias vivas: sistema de utilização de plantas medicinais projetada para pequenas comunidades. 2 ed. Fortaleza: EUFC, 1994.

2 MURRAY, P.R. e col.. Microbiologia médica. 3 ed. Rio de Janeiro: Guanabara Koogan, 2000. 